\title{
Knjižne objave domače produkcije v sociologiji kulture'
}

\section{0}

${ }^{\star}$ Althusser, Louis in drugi: Ideologija in estetski učinek. Zbornik; ur. Zoja Skušek. Ljubljana: Cankarjeva založba.

Kerševan, Marko: Razredna analiza in marksistična družbena teorija: razprave iz marksistične obče sociologije in sociologije religije. Ljubljana: Delavska enotnost.

Skušek, Zoja. Gledališče kot oblika spektakelske funkcije. Ljubljana: Univerzum.

\section{1}

Rotar, Braco: Pomeni prostora. Ideologije v urbanizmu in arhitekturi. Ljubljana: Delavska enotnost.

Rotar, Braco: Govoreče figure. Eseji o realizmu. Ljubljana: Univerzum.

Močnik, Rastko: Mesčevo zlato: Prešeren v označevalcu. Ljubljana: Univerzum.

*Freud, Sigmund in drugi: Psihoanaliza in kultura. Zbornik; ur. Rastko Močnik in Slavoj Žižek. Ljubljana: Državna založba Slovenije.

\section{2}

${ }^{\star}$ Chesterton, G. K. in drugi: Memento umori: teorija detektivskega romana. Zbornik; ur. Slavoj Žižek in Rastko Močnik. Ljubljana: Državna založba Slovenije.

Roter, Zdenko, Kerševan, Marko: Vera in nevera v Sloveniji: 1968-1978. Maribor: Obzorja.

\section{3}

Močnik, Rastko: Raziskave za sociologijo književnosti. Ljubljana: Državna založba Slovenije.

\section{4}

Kerševan, Marko: Religija v samoupravni družbi. Ljubljana: Državna založba Slovenije.

1 Samo knjižne izdaje slovenskih avtoric in avtorjev v slovenščini po letu 1980 in po časovnem zapovrstju. Dodali smo tri zbornike prevodov, ki so določili terminologijo in tudi sicer močno vplivali na teoretsko produkcijo. Označili smo jih $z^{*}$. 


\section{5}

Rotar, Braco: Risarji: učenjaki. Ljubljana: Delavska enotnost.

Močnik, Rastko: Beseda besedo. Ljubljana: ŠKUC.

\section{6}

Saksida, Iztok: Šola. Učitelj, mati in otrok. Ljubljana: Delavska enotnost.

\section{7}

Rotar, Braco: Pigmalionova pregreha. Ljubljana: Krt.

\section{8}

Baskar, Bojan: Latinščine, prosim! Latinščina in njeno izganjanje na Slovenskem, 18491987. Ljubljana: Krt.

\section{9}

Žagar, Igor Ž.: Zagatnost performativnosti ali Kako obljubiti. Ljubljana: Državna založba Slovenije.

Kerševan, Marko: Religija in slovenska kultura: ljudska religioznost, civilna religija in ateizem v Sloveniji. Ljubljana: Znanstveni inštitut Filozofske fakultete: Partizanska knjiga.

\section{2}

Kerševan, Marko: Vstop v krščanstvo drugače: protestantska teologija (Karla Bartha) v našem času in prostoru. Ljubljana: Cankarjeva založba.

\section{3}

Močnik, Rastko: Extravagantia. Ljubljana: Studia humanitatis.

\section{4}

Kump, Sonja: Akademska kultura. Ljubljana: Znanstveno in publicistično središče. 


\section{5}

Vogrinc, Jože: Televizijski gledalec. Koncept televizijskega komunikacijskega razmerja kot izhodišče za teorijo televizije. Ljubljana: ŠKUC - Znanstveni inštitut Filozofske fakultete.

Močnik, Rastko: Extravagantia II. Koliko fašizma? Ljubljana: ISH.

\section{7}

Nežmah, Bernard: Kletvice in psovke. Ljubljana: Nova revija.

\section{8}

Kreft, Lev: Perspektivovci in perspektivaši: portret skupine. Ljubljana: ZPS.

\section{9}

Mrgole, Albert: Malopridna mladež med zaščitniki in preganjalci. Ljubljana: Založba ${ }^{*} \mathrm{cf}$. Močnik, Rastko: 3 teorije. Ideologija, nacija, institucija. Ljubljana: Založba / ${ }^{\star} \mathrm{cf}$. Škamperle, Igor: Magična renesansa. Ljubljana: Študentska založba.

\section{2}

Breznik, Maja: Obrt in učenost. Koper: Annales.

\section{4}

Breznik, Maja: Kulturni revizionizem: kultura med neoliberalizmom in socialno odgovorno politiko. Ljubljana: Mirovni inštitut.

Grgič, Matejka, Žagar, Igor Ž.: Čas in dejanje v jeziku. Ljubljana: Založba /*cf.

Vidmar Horvat, Ksenija: Uvod v sociologijo kulture. Učbenik za prve letnike sociologije. Ljubljana: Filozofska fakulteta.

\section{5}

Breznik, Maja, Novljan, Silva, Jug, Janez, Milohnić, Aldo: Knjižna kultura. Ljubljana: UMco.

Milohnić, Aldo, Breznik, Maja, Hrženjak, Majda, Bibič, Bratko: Kultura d. o. o.: materialni pogoji kulturne produkcije. Ljubljana: Mirovni inštitut. 
Centrih, Lev in drugi: Marksizmi in jezikoslovje. Zbornik. Ljubljana: Agregat.

Kerševan, Marko: Svoboda za Cerkev, svoboda od Cerkve: Cerkev in sodobna družba. Ljubljana: Sophia.

Blatnik, Andrej, Rugelj, Samo, Breznik, Maja, Duša, Zdravko, Grilc, Uroš, Košir, Manca, Kovač, Miha: Zgubljeno v prodaji: slovenska knjiga med državo in trgom v tretjem tisočletju (sedem pogledov na prihodnost slovenske knjige). Ljubljana: UMco.

\section{6}

Kerševan, Marko: Protestantizem, slovenska identiteta in združujoča se Evropa. Ljubljana: Znanstvenoraziskovalni inštitut Filozofske fakultete.

Močnik, Rastko: Julija Primic v slovenski književni vedi. Ljubljana: Sophia.

\section{7}

Culiberg, Luka: Japonska med nacionalnim mitom in mitološko nacijo. Ljubljana: Založba $/{ }^{*} \mathrm{cf}$.

Močnik, Rastko: Veselje v gledanju. Ljubljana: Založba /*cf.

Rotar, Braco. Odbiranje iz preteklosti: okviri, mreže, orientirji, časi kulturnega življenja $v$ dolgem 19. stoletju. Koper: Annales.

Kramberger, Taja: Historiografska divergenca: razsvetljenska in historistična paradigma. O odprti in zaprti epistemični strukturi in njunih elaboracijah. Koper: Annales.

\section{8}

Habjan, Jernej: Janus, Prokrust, Bahtin: kvadratura Bahtinovega kroga. Ljubljana: LUD Literatura.

\section{9}

Breznik, Maja: Kultura danajskih darov. Ljubljana: Sophia.

Močnik, Rastko: Spisi iz humanistike. Ljubljana: Založba /*cf.

Vogrinc, Jože: Historični materializem in humanistične vede. Ljubljana: Studia humanitatis.

Milohnić, Aldo: Teorije sodobnega gledališča in performansa. Ljubljana: Maska.

Cindrič, Alojz: Študenti s Kranjske na dunajski univerzi 1848-1918. Ljubljana: UL.

Lešnik, Bogdan: Temelji psihoanalize. Opombe h konceptom. Ljubljana: Založba /*cf. 


\section{0}

Cindrič, Alojz: Študenti s Kranjske na dunajski univerzi v prvi polovici devetnajstega stoletja 1804-1848. Ljubljana: UL.

Kramberger, Taja, Rotar, Drago Braco: Misliti družbo, ki (se) sama ne misli. Ljubljana: Sophia.

\section{1}

Centrih, Lev: Marksistična formacija. Zgodovina ideoloških aparatov komunističnega gibanja 20. stoletja. Ljubljana: Založba $/{ }^{*} \mathrm{cf}$.

Breznik, Maja, Stepančič, Lilijana, Lipovšek, Brigita, Pivec, Helena, Širca, Majda, Tivadar, Blanka: KKIPS: kulturne in kreativne industrije po slovensko. Ljubljana: Ministrstvo za kulturo.

Breznik, Maja in drugi: Posebni skepticizem v umetnosti. Ljubljana: Sophia.

Kerševan, Marko: Sociologija - marksizem - sociologija religije: izbrani spisi. Ljubljana: Znanstvena založba Filozofske fakultete.

Nežmah, Bernard: Kletvice in psovke, 2., dopolnjena izd. Ljubljana: Družba Piano.

Kolšek, Katja, Gregorc, Tomaž (ur.): Prihodnost znanosti. Neoliberalizem, univerza in politika sodobnega znanstvenega raziskovanja. Novo mesto: Goga.

Kramberger, Taja, Rotar, Drago Braco: Nevidne evidence: misliti idola tribus. Ljubljana: Sophia.

\section{2}

Vogrinc, Jože: Popularna godba: eseji ob poslušanju. Maribor: Subkulturni azil.

Kerševan, Marko: Protestanti(sti)ka. Ljubljana: Cankarjeva založba.

Nežmah, Bernard: Časopisna zgodovina novinarstva na Slovenskem med letoma 17971989. Ljubljana: Študentska založba.

Habjan, Jernej (ur.): Diskurz. Od filozofije govorice do teorije ideologije. Ljubljana: Pedagoški inštitut. http://193.2.222.157/Sifranti/StaticPage.aspx?id=122 